\title{
INSTRUMENTSIFOR SURFACE AND UPPER AIR MEASUREMENTS FROM MARINE PLATFORMS
}

\author{
E. T. Harding, Capt. USN \\ Nava! Weather Service, Washington, D. C.
}

\section{Summary}

There are two major problems with our oceanic observational program: 1) there are insufficient observations to cover the oceans adequately, and those that are taken are poorly spaced in time; and 2) ship reports of weather are not as accurate as those taken on land.

Of the solutions offered for these problems, satellites provide the major hope for the future. Other possible solutions are buoy systems, constant level balloons, commercial aircraft observations, weather reconnaissance aircraft, and commercial shipping. The author envisions a mix of elements from each of the above, forming a substantial oceanic observing network. Eventually, with scientific advances, satellites will take over most of the work in this field.

The total system, as postulated by the author, will have four parts:

1) Control and communications

2) Surface observations

3) Upper air observations

4) Buoys

Instrumentation for ocean surface observations would eventually be automated, and monitored on shore. The following list describes the preferred sensor for each of the various parameters:

Element

Position

Time

Pressure

Sensor
IRIS, LORAN or OMEGA
systems
Chronometer
Aneroid precision capsule, operat-
ing in a controlled-temperature
cavity. A change in pressure
moves a core within a differential
transformer to provide an elec-
trical output proportional to the
change in pressure. This output
is amplified and passed to the
display unit to actuate the
digital readout for pressure.

Air temperature

Wind speed and direction

Sea temperature

Waves

Humidity

Precipitation

Water temperature profile

Cloud height

Sunshine duration and insolation
Platinum resistance wire the resistance of which is a linear function of temperature. Resistance changes the balance of a bridge network to provide an electrical output proportional to the change in temperature.

Sonic anemometer that utilizes an electromagnetic probe and an acoustic probe, separated as far apart as possible, and intersecting at some distance from the ship. The sonic probe bombards the air with sonic pulses, causing a chemical change in the air molecules, and a change in the electric constant at the intercept point. This, in effect, produces a target which is hit by the electromagnetic probe to provide an output proportional to the movement of the target or wind velocity.

Near-surface reference temperature device. A thermistor probe located in the injection intake near the skin of the ship, with remote readout at desired location.

Infrared wave measuring device, bow mounted, which scans $\sim 15$ $\mathrm{ft}$ ahead of the ship and measures distance to water. Ship motion must be measured and integrated with $I R$ readings.

Peltier effect dew-pointer. Dew formation on cooled surface sensed by small thermistor and derived temperature is amplified as an electrical signal and passed to readout point.

Selective precipitation indicator. An electronic instrument of composite design to sense presence of dew, frost, drizzle, rain or snow; to differentiate and report on incidence, duration and type.

Expendable bathythermograph.

To be computed from upper air soundings (on upper air ships only).

Photocell with automatically controlled sensitivity. 